\title{
Massive haemoptysis from a bougie intubating catheter in a patient with endobronchial sarcoid
}

\author{
Mark Alter, ${ }^{1}$ Benjamin Peake, ${ }^{2}$ Simon Grodski, ${ }^{3,4}$ Laurence Weinberg ${ }^{2,5}$
}

'Department of Anaesthesia, Box Hill Hospital, Box Hill, Victoria, Australia

${ }^{2}$ Department of Anaesthesia, Austin Hospital, Heidelberg, Victoria, Australia

${ }^{3}$ Department of Surgery, Alfred Hospital, Melbourne, Victoria, Australia

${ }^{4}$ Monash University, Clayton, Victoria, Australia

${ }^{5}$ Surgery and Anaesthesia Preoperative Pain Medicine Unit, University of Melbourne, Melbourne, Victoria, Australia

\section{Correspondence to} Associate Professor Laurence Weinberg, laurence.weinberg@ austin.org.au

Accepted 26 May 2016
CrossMark

To cite: Alter $M$, Peake $B$, Grodski S, et al. BMJ Case Rep Published online: [please include Day Month Year] doi:10.1136/bcr-2016215936

\section{DESCRIPTION}

A 61-year-old man with biopsy-proven sarcoidosis on prednisolone (10 $\mathrm{mg}$ daily) presented for elective hemithyroidectomy for a retrosternal goitre. Preoperative investigations revealed bilateral hilar adenopathy on chest radiograph, with preoperative respiratory function tests (RFTs) showing an obstructive pattern (reduced forced expiratory volume in $1 \mathrm{~s} /$ normal forced vital capacity). Preoperative haematological and biochemical investigations were normal.

Following routine induction of anaesthesia (propofol $2.5 \mathrm{mg} / \mathrm{kg}$, fentanyl $3 \mu \mathrm{g} / \mathrm{kg}$ ) and neuromuscular blockade (rocuronium $0.6 \mathrm{mg} / \mathrm{kg}$ ), airway laryngoscopy using a conventional Macintosh blade (size 4) revealed that only the posterior extremity of the glottis was able to be visualised (Grade 2b modified Cormack-Lehane direct laryngoscopy classification). To facilitate tracheal intubation, a lubricated single-use bougie intubating catheter (Frova, Cook Medical, Bjaeverskov, Denmark) was inserted directly into the trachea and then used as a guide over a size 7.5 flexible nerve monitoring endotracheal tube (ETT) (NIM Flex EMG ETT, Medtronic, Xomed Inc, Jacksonville, Florida, USA), which was railroaded. As the bougie was inserted, normal 'clicks' were felt as the tip was advanced over the tracheal rings, and a normal 'hold up' was noted at $30-40 \mathrm{~cm}$ depth. The ETT was secured, cuff inflated and the bougie removed. Immediately, blood was noted to fill the entire ETT, filter and anaesthesia circuit. While intermittently ventilating the patient with 100\% oxygen (tidal volume $500 \mathrm{~mL}$, positive end expiratory pressure $10 \mathrm{~cm} \mathrm{H}_{2} \mathrm{O}$ ), $950 \mathrm{~mL}$ bright red blood was suctioned from the ETT through a $16 \mathrm{G}$ suction catheter. Flexible bronchoscopy revealed multiple endobronchial sarcoid lesions as the source of bleeding (figure 1). Iced saline lavage and the application of topical epinephrine $(5 \mathrm{~mL}$ 1:10 000) were carried out on the bleeding lesions via a side channel of the bronchoscope, and after $15 \mathrm{~min}$ the bleeding resolved. Surgery was abandoned and the patient transferred to the intensive care unit with the ETT in situ. There was no further bleeding and the patient's trachea was successfully extubated 2 hours later. Prednisolone $(50 \mathrm{mg}$ daily) was started for a 14-day period and subsequently weaned to the patient's normal $10 \mathrm{mg}$ daily dose. Repeat bronchoscopy was performed a fortnight later, demonstrating complete resolution of the bronchial lesions. Elective hemithyroidectomy was rescheduled and proceeded without incident 1 month later.

We describe a rare case of massive haemoptysis as a result of direct trauma from an intubating catheter to bronchial sarcoid lesions (figure 1). Anaesthetists should take extreme caution to avoid airway trauma when using intubating bougies in this patient group. In such cases, prior to airway instrumentation, flexible bronchoscopy should be considered to exclude endobronchial sarcoid and, if
A

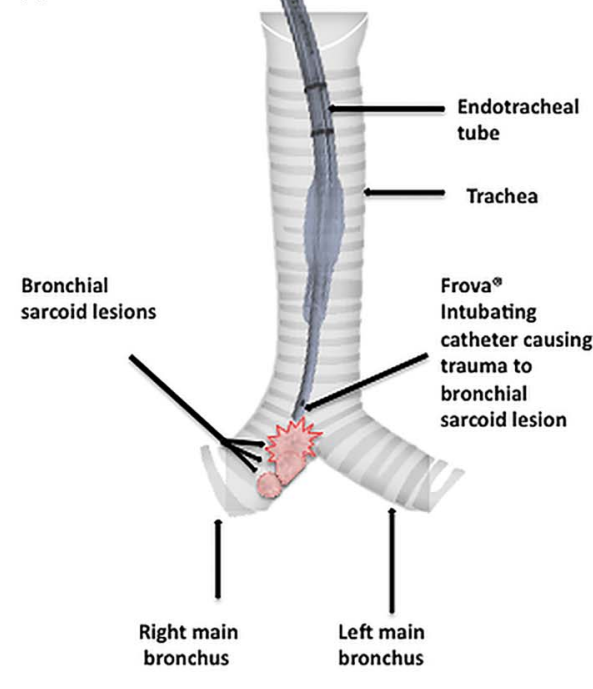

Figure 1 (A) Reconstructed diagram demonstrating the mechanism of massive haemoptysis where the intubating Frova catheter resulted in direct trauma to the bronchial sarcoid lesions. (B) Actual bronchoscopic view of the patient's tracheal bifurcation, with bronchial sarcoid lesions present at the level of the carina and right main bronchus.

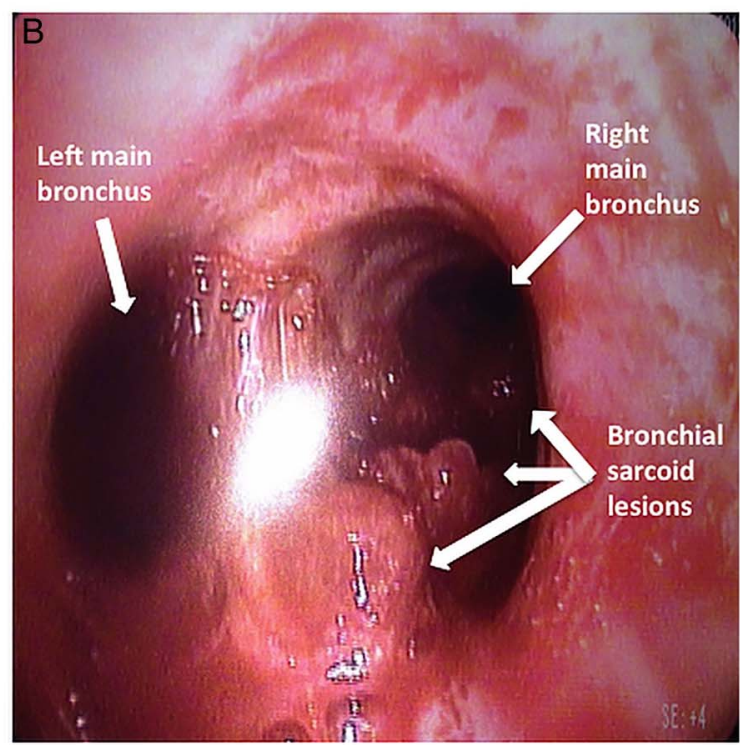

Alter M, et al. BMJ Case Rep 2016. doi:10.1136/bcr-2016-215936 
present, a bougie catheter should be avoided. Use of videolaryngoscopes to manage a difficult airway or facilitate ETT should be strongly considered in preference to 'blind' instrumentation of the airway. If a bougie intubating catheter is used, the 'hold up' sign ${ }^{1}$ should not be elicited. The optimal emergency management of massive haemoptysis from endobronchial sarcoid is unclear, however, if bleeding does not resolve spontaneously or with bronchoscopic techniques described above, emergent consultation from an interventional radiologist or thoracic surgeon

\section{Learning points}

- Bougie intubating catheters should be avoided in patients with bronchial sarcoid, due to risks of iatrogenic massive haemoptysis.

- Flexible bronchoscopy should be considered in all patients with sarcoid if an intubating catheter is planned for use.

- Use of videolaryngoscopes to manage a difficult airway or facilitate endotracheal tube insertion should be considered in patients with endobronchial sarcoid, in preference to 'blind' airway instrumentation. should be obtained for consideration of bronchial artery embolisation or emergency thoracotomy. ${ }^{2}$ RFTs in patients with bronchial sarcoidosis characteristically reveal a restrictive pattern; ${ }^{3}$ in patients whose RFTs demonstrate obstructive respiratory physiology, a heightened awareness for endobronchial sarcoid is required.

Contributors MA was the principle anaesthetist, collected all the patient data and clinical images, and assisted with the writing of the manuscript. BP performed the literature review, helped prepare the clinical images and assisted with the writing of the manuscript. SG was the principle surgeon and assisted with the writing of the manuscript. LW helped perform the literature review, prepared the clinical images, helped write the manuscript and was the coordinating author.

Competing interests None declared.

Patient consent Obtained.

Provenance and peer review Not commissioned; externally peer reviewed.

\section{REFERENCES}

1 Marson BA, Anderson E, Wilkes AR, et al. Bougie-related airway trauma: dangers of the hold-up sign. Anaesthesia 2014;69:219-23.

2 Loh GA, Lettieri CJ, Shah AA. Bronchial arterial embolization for massive haemoptysis in cavitary sarcoidosis. BMJ Case Rep 2013;2013:pii: bcr2012008268.

3 Dunn TL, Watters LC, Hendrix C, et al. Gas exchange at a given degree of volume restriction is different in sarcoidosis and idiopathic pulmonary fibrosis. Am J Med 1988;85:221-4.

Copyright 2016 BMJ Publishing Group. All rights reserved. For permission to reuse any of this content visit http://group.bmj.com/group/rights-licensing/permissions.

BMJ Case Report Fellows may re-use this article for personal use and teaching without any further permission.

Become a Fellow of BMJ Case Reports today and you can:

- Submit as many cases as you like

- Enjoy fast sympathetic peer review and rapid publication of accepted articles

- Access all the published articles

- Re-use any of the published material for personal use and teaching without further permission

For information on Institutional Fellowships contact consortiasales@bmjgroup.com

Visit casereports.bmj.com for more articles like this and to become a Fellow 